\title{
The prevalence, characteristics and outcome of seizure in tuberculous meningitis
}

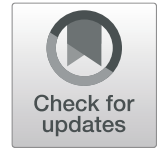

Ammar Taha Abdullah Abdulaziz ${ }^{1,2}$, Jinmei Li ${ }^{1}$ and Dong Zhou ${ }^{1 *}$

\begin{abstract}
Seizures are a common finding in patients with tuberculous meningitis (TBM), and associate with four times increased risk of death and neurological disability, especially in children. It has been reported that brain inflammation, diffuse neuronal injury, and reactive gliosis may all contribute to the pathogenesis of seizures in TBM. Early seizure onset may be associated with meningeal irritation and cerebral oedema; while, the late seizures are usually due to infarction, hydrocephalus, tuberculoma and paradoxical response. Moreover, recurrent uncontrolled seizures can evolve to status epileptics resulting in an increased risk of chronic epilepsy and poor prognosis. Therefore, this review aimed to assess the frequency of seizures in patients with TBM, and discuss the etiologies, mechanisms, and characteristics of seizures in TBM. Besides, we have searched the literature to identify the prognostic factors for chronic epilepsy after TBM.
\end{abstract}

Keywords: Seizure, Tuberculous meningitis, Neuronal injury, Epilepsy

\section{Background}

Tuberculous meningitis (TBM) is the most devastating form of extrapulmonary TB, carrying significantly higher mortality and neurological disability among infected individuals, especially in low-income countries $[1,2]$. The clinical characteristics of TBM include fever, headache, vomiting, impaired consciousness, focal neurological signs, and seizures [3]. Seizure is a common feature of TBM that may develop at any time point throughout the disease course, with an estimated incidence of 17 to 93\% [4]. Seizures associated with TBM infection can be either acute symptomatic or unprovoked seizures. Acute symptomatic seizures usually occur within the first 2 weeks, and sometimes even later. Although they subside once the acute infection is over and may not recur; there is often an increased risk of developing subsequent epilepsy. Whereas unprovoked seizures occur later after the acute phase of TBM and have a propensity to recur [5]. Status epileptics (SE) is also not uncommon finding in patients with TBM.

The current data is showing that seizures in TBM are more common in children than adults; this may be attributed to the immaturity of the brain $[4,6-8]$. Over

\footnotetext{
* Correspondence: zhoudong66@yahoo.de

${ }^{1}$ Department of Neurology, West China Hospital, Sichuan University, 37 Guo Xue Xiang st, Chengdu 610041, China

Full list of author information is available at the end of the article
}

half of children with TBM may experience seizures at any time point, but more often during the late stage [9]. There is accumulating data suggested that brain inflammation and the subsequent neuronal injury and reactivation of glial cells play an essential role in seizure induction following central nervous system (CNS) infection [10-12]. The underlying etiology of seizures in TBM is multifactorial, therefore the type and duration of treatment may vary between individual cases depending on the possible underlying cause of convulsion. In patients with $\mathrm{CNS}$ infections, recurrent seizures are common observation after the first seizure; therefore, these patients are probably in need of prophylactic antiepileptic drugs (AEDs) to prevent further seizure recurrence, at least during the acute phase of the disease [13].

In this review we first report the incidence and prevalence of seizures in patients with TBM, and discuss the etiological factors associated with the development of seizures. Secondly, we review the pathogenesis and mechanisms of seizure and acquired epilepsy caused by TBM; as well as the clinical and electrophysiological characteristics of these seizures. Finally, we identify the predictors of chronic epilepsy following TBM infection; and report seizure prognosis in TBM. To our knowledge this is the first paper reviewing seizures in TBM so far.

(c) The Author(s). 2020 Open Access This article is distributed under the terms of the Creative Commons Attribution 4.0 International License (http://creativecommons.org/licenses/by/4.0/), which permits unrestricted use, distribution, and 


\section{Epidemiology}

Seizure prevalence in TBM varies widely based on many factors such as the patient's age, human immunodeficiency virus (HIV) co-infection, socioeconomic status of affected individuals, study design, and the length of follow-up. Overall, seizures have been reported in 17-93\% of TBM patients, and it can occur at any time point throughout the disease course $[7,8,14-21]$. Seizures in TBM can be either acute symptomatic or unprovoked seizures; the frequency of acute symptomatic seizures in TBM is estimated between 16.3 and $31.5 \%[20,21]$. Although acute seizures in TBM is relatively higher than that in bacterial meningitis, viral encephalitis is associated with the highest incidence of post-infection seizures, reported in 62 to $67 \%$ of the cases [22]. This is could be attributed to the fact that parenchymal involvement is often more severe in patients with encephalitis than those with meningitis [22-25]. Children with TBM are more likely to experience seizures relative to adults; this may be attributed to the immaturity of CNS, blood-brain barrier, and the immune system of this vulnerable group $[4,26]$. The incidence of seizures in children with TBM has been estimated between 50 and $74 \%$ [4, 26-29]; with higher rates being reported in pediatric patients under the age of 4 years [30-33]. While the reported risk of late unprovoked seizures among CNS infection survivors in the developed countries is estimated at 6.8$8.3 \%$, it is much higher in resource-poor countries [34]. Moreover, the highest incidence of late unprovoked seizures had been reported to occur in the first 5 years after infection [35].

Seizures are less likely to occur in HIV negative patients with TBM compared to those with HIV co-infection; with an estimated range from 4 to $11 \%$ [36-39]. A study comparing TBM patients with and without HIV infection has found that acute symptomatic seizures occurred in $30 \%$ of HIV positive cases compared to just $9.5 \%$ in those without HIV infection [40]. In addition, tuberculosis (TB) burden is significantly affected by the socio-economic gap between and within countries and communities, with the poorer groups having a higher risk of TB infection, including TBM [4, 41]. A poor socio-economic status is often associated with advanced disease stage at presentation and limited access to healthcare services; thereby, developing more complications including higher prevalence and incidence of seizures.

Seizures also can be the initial presenting symptom of TBM, even in patients with negative magnetic resonance imaging (MRI) findings at admission [3, 26]. In children, seizures are the presenting symptom in $10-20 \%$ of the affected cases, and over $50 \%$ of children with TBM develop seizures at the initial days of admission [42]. While in adults, seizures were reported as the initial presenting feature in $10-15 \%$ of TBM cases $[28,43]$.

\section{Etiology}

The underlying etiology of seizures in TBM is multifactorial depending on different pathophysiological changes that may simultaneously occur in the central nervous system during the disease course. Some of these pathological processes develop early after the disease onset and often response well to early management, while other pathological changes continue to damage the brain tissues resulting in devastating complications, including neurological deficits and seizures [4]. Meningeal irritation, increased intracranial pressure (ICP), cerebral oedema, tuberculoma, hydrocephalus, and cerebral ischemia were associated with convulsions in patients with TBM $[3,4]$. Bharucha and colleges have also reported that TBM patients with meningeal irritation, tuberculoma, cerebral oedema, arteritis, infarction, hydrocephalus, and hyponatremia were more likely to experience seizures [44]. Moreover, in TMP patients, refractory seizures are more commonly associated with uncontrolled inflammation and severe brain injury that may eventually result in chronic epilepsy.

Drug-induced seizures in TBM have also been reported in many studies. In a randomized controlled trial, seizures were reported in $17 \%$ of patients using intensified therapy with Levofloxacin, while none of those using only the standard anti-TB regimen has developed seizures during the treatment period [45]. Furthermore, a recently published meta-analysis has also concluded that fluoroquinolones use in TBM was associated with a higher incidence of seizures [46]. Isoniazid, an anti-TB drug, was found to have seizure-inducing properties, and Isoniazid overdose has been reported to induce seizures [47]. Beside the ongoing pathological changes of TBM that play an essential role in reducing seizure threshold; these medications could further decrease the seizure threshold; thus, increasing the incidence of seizures among TBM patients receiving these particular medications.

\section{Mechanism}

Seizures can occur at different disease stages depending on the underlying pathophysiologicalmechanism. Early seizures are usually associated with meningeal irritation, cerebral oedema, and raised intracranial pressure; whereas, hydrocephalus, infarction, tuberculoma, and hyponatremia provoke late-onset seizures $[4,48]$. Meningeal irritation and cerebral oedema represent the acute immune reaction in the brain as a response for Mycobacterium tuberculosis infiltration. The recently accumulating preclinical and clinical evidence suggest that inflammation plays a crucial role in triggering seizures $[10,11]$. CNS infections often induce severe inflammatory reactions and are a major risk factor for seizures. In developed countries, it is estimated that 6.88.3\% of CNS infection survivors develop seizures, while the rates are much higher in the developing world [34]. 
CNS inflammatory reaction is characterized by the activation of astrocytes, microglia, and endothelial cells of the blood-brain barrier, along with the infiltration of immune cells and plasma proteins resulting in the upregulation of series of inflammatory mediators [49-52]. Many studies had found that pro-inflammatory mediators, such as COX-2, IL-1b, IL-6, PGE2, HMGB1, TNF- $\alpha$ TGF- $\beta$, TLR4, and NOX2 play essential roles in the generation and exacerbation of seizures [53-56]. Furthermore, researchers have demonstrated that seizures also can increase the permeability of blood-brain barrier (BBB), thereby intensifying the neuroinflammation via the extravasation of immune cells and inflammatory mediators from blood vessels into the brain tissue $[49,51,52]$. A recent study has also reported that neuroinflammation and reactive gliosis following diffuse neuronal injury play a major role in seizure induction; and recurrent seizures are associated with massive glial activation and inflammatory responses in the epileptogenic cortex [12].

Cell-mediated immunity is important for tuberculomas' formation, and adequate response of host's immune system to Mycobacterium bacilli may lead to the development of either caseating or non-caseating granulomas at the site of dissemination; these lesions remain clinically silent until they induce a mass effect and lower seizure threshold [57-59]. In addition, raised ICP is also one of the common causes of seizures in TBM $[60,61]$, and various factors may contribute to the mechanism of increased ICP. In the acute phase, it could be attributed to gross cerebral oedema associated with TB inflammation $[4,62]$. However, In subacute and chronic cases, hydrocephalus is the most common cause of raised ICP [4].

The pathological changes of TBM may extend to involve the brain's parenchyma and infiltrate intracranial blood vessels, causing vasculitis and subsequent infarction. These processes may lead to cytotoxicity, vasogenic oedema, and the release of inflammatory molecules. The leptomeningeal inflammatory exudates can cause hydrocephalus by either obstructing the flow of cerebrospinal fluid (CSF) or impairing its absorption, which may lead to severely high ICP and subsequent seizures.

It is also worth mentioning that isoniazid, one of the most commonly used anti-tuberculosis drugs, has seizureinducing properties. Temmerman and colleges had reported that isoniazid overdose was associated with repetitive seizures refractory to antiepileptic drugs, metabolic acidosis, and coma [47]. Moreover, unprovoked seizures were also observed even after single conventional doses of this drug [63].

\section{Characteristics}

Although seizure is a common finding in patients with TBM, data regarding the clinical characteristics, time of onset and type of seizures remain not completely understood.

\section{Time of onset}

Seizures in TBM can occur at different time points depending on the different underlying pathologies. Early seizure onset may be attributed to meningeal irritation and cerebral oedema; while late-onset seizures are usually associated with infarction, hydrocephalus, and tuberculoma [3, 4]. Misra UK. and colleagues reported that most of the early-onset seizures were due to meningeal irritation; whereas, late-onset seizures were more commonly associated with tuberculoma, infarction, and hyponatremia [48]. In their study, $34.2 \%$ of the patients experienced seizures during the disease course, with the majority of the cases $(70.4 \%)$ had late-onset convulsions [48]. Paradoxical response is also a common finding in TBM and may associate with the development of late-onset seizures. In one study, paradoxical worsening was reported in 22 (64.7\%) patients, out of them 12 had experienced lateonset seizures, which were more commonly related to tuberculoma [64]. Another study from India has also found that paradoxical worsening related seizures were more frequently late-onset seizures [48].

\section{Type of seizure}

Seizure development in TBM and its type may vary based on the underlying pathologies or the affected brain regions. Seizures in TBM are either focal, that may or may not evolve to secondary generalized seizures, or generalized tonic clonic seizures (GTCS) [4]. In contrast, seizures in viral encephalitis are more likely to be GTCS or focal with secondary generalization [5]. Whether the seizure is focal or generalized, it may eventually evolve to convulsive or non-convulsive SE in some cases [26, 65]. Seizures due to meningeal irritation, cerebral oedema and raised ICP are commonly generalized seizures that emerge during the earlier phase of TBM [4]. In contrast, tuberculomas and infarctions are more likely to induce focal seizures rather than generalized ones. A study from the UK reported that out of 38 patients with TBM, 20 (50\%) patients had seizures. Focal onset was noted in 15 (39.5\%); whereas GTCS were observed in $5(13.2 \%)$ patients, with all patients with isolated tuberculomas developed focal seizures [27]. Another study included 20 patients with CNS tuberculomas found that $60 \%$ of the cases have developed focal seizures with secondary generalization and only $30 \%$ of the patients presented with primary generalized seizures [66]. Furthermore, in a recent study, out of 79 Indian patients with TBM, 27 (34.2\%) patients had seizures. Focal seizures were the most frequent type, reported in $12(15.2 \%)$, followed by focal to bilateral in $8(10.1 \%)$, and generalized seizures in $7(8.9 \%)$ patients [48]. In this study, the common causes of seizures were tuberculoma in $33.3 \%$, multiple associations in $33.3 \%$ and infarction in $14.8 \%$ of the cases [48]. 
While in another study where over $60 \%$ of TBM patients had developed hydrocephalus, among the 11 (34.4\%) patients presented with clinical seizures, 9 had generalized tonic clonic seizures and 2 had partial seizures [67]. Furthermore, a study from India reported that 101 out of 136 children with TBM had seizures, and among them 57 (42\%) patients experienced seizures before admission, while 44 (32\%) cases developed seizure after hospitalization. In this study, GTCS were reported in 59 (43.4\%) patients, followed by focal seizures (28\%) and tonic spasm (3\%). This is maybe attributed to the fact that cerebral oedema was found to be the most common cause of seizures (58\%) followed by hyponatremia (48\%) and SIADH (35\%) [68].

$\mathrm{SE}$ is more common in resource-limited countries, thus contributing to the higher prevalence and incidence of epilepsy after cerebral infection in the developing world. Moreover, the frequency of SE among children in these countries is three times higher than adults [5].

SE including convulsive and non-convulsive, has also been reported in TBM $[26,65,69-71]$. In a recent study from India, SE occurred in $22.2 \%$ of TBM patients presented with seizures [48]. Interestingly, all these patients had multiple causes, including tuberculomas, infarctions, and hydrocephalus.

\section{EEG findings}

TBM has been reported to induce more abnormalities on Electroencephalography (EEG) than other meningitis [72], especially in children [73]. The EEG changes in patients with TBM vary according to the site of the ongoing inflammatory process [74]. In patients with TBM, EEG may demonstrate diffuse slowing with or without focal changes and epileptic discharges, depending on the severity of TBM symptoms [3, 21]. Researchers have also found that the involvement of meninges and cerebral cortex often results in a typical pattern of diffuse slowing on EEG [3, 67]. Furthermore, the absence of welldefined lateralization on EEG is a sign of a widespread meningeal inflammation as the most likely cause of the seizure in these patients [3]. Patwari and colleagues found that TBM patients presented with GTCS had generalized dysrhythmia with slow activity, and multiple spike and wave pattern; while those presented with focal seizures had interhemispheric asymmetry and focal spike and wave pattern, which were more likely due to focal intracranial lesions such as tuberculoma and infarction [4]. This study has also suggested that the presence of epileptiform discharges on EEG may predict chronic epilepsy [4]. Gunawan and colleagues have reported abnormal EEG activity in $75 \%$ of the patients, out of them $77 \%$ had epileptogenic activities; moreover, they found a strong correlation between epileptic spikes on EEG and the development of clinical seizures [30]. However, a recent study from China has concluded that the presence of epileptiform discharge on EEG was not associated with poorer outcome [75]. In TBM patients with convulsions, epilepitform discharges are less common finding relative to slow activity, especially in adult patients. Although Kalita J. et al. has reported clinical seizures in 11 adult patients with TBM, epileptiform activity was noted in only 4 patients [67]. EEG is often more sensitive in children than adults; In a study included 12 children with TBM, epileptic activity was detected in 8 out of the 10 (83.3\%) children presented with clinical seizures [30]. It is also worth mentioning that EEG recording in TBM patients with non-convulsive SE often shows continuous rhythmic activity. Arman et al. had reported a case presented with impaired consciousness and persistent seizure activity on EEG; particularly, continuous sharp and slow-wave activity that was suppressed after SE therapy and the patients regain her consciousness [26].

EEG can be used to detect the underlying seizure activity and predict the risk of secondary epilepsy in patients with TBM $[4,30]$. Moreover, EEG may help to localize the underlying lesions, exclude non-convulsive SE, and provide a rough guide to the degree of cortical and subcortical dysfunction in TBM patients $[76,77]$.

\section{Predictors of chronic epilepsy}

The mechanisms of chronic epilepsy following TBM are not well established. However, prolonged inflammatory stimulation by either chronic inflammation or by seizures themselves and structural damage of brain tissues resulting from infarction, space-occupying lesions, and gliosis may all constitute to epileptogenesis. Several factors have been reported to associate with increased risk of epilepsy following TBM infection including the patient's age, recurrent seizures and SE, tuberculoma, infarction, hippocampal sclerosis, and persistent epileptic activity on EEG.

\section{Young age}

Children with TBM are more likely to develop seizures during the disease course compared to adults; this could be attributed to the immaturity of the brain in these patients [4, 26]. The younger the age, the higher is the incidence of seizures and subsequent epilepsy [4]. Moreover, the frequency of SE after cerebral infection in children can be 3 -fold higher than adults, thus contributing to the higher incidence and prevalence of epilepsy in this vulnerable group [5, 78]. In addition, many studies had found that the occurrence of meningitis at early-life is associated with mesial temporal sclerosis and chronic epilepsy [33, 79, 80], especially before the age of 4 years; authors have proposed that mesial temporal region is generally vulnerable and more sensitive to epileptogenic 
damage at a young age; while at an older age, the region is more mature and thereby more resistant to damage [31].

\section{Repetitive seizures and status epileptics}

In TBM patients, the occurrence of repetitive seizures despite adequate and appropriate medical management is associated with a higher incidence of structural abnormalities and an increased risk of chronic epilepsy [68]. Furthermore, recurrent seizures increase the permeability of $\mathrm{BBB}$ and intensify neuroinflammation resulting in severe neuronal injury and gliosis. These changes contribute to epileptogenesis and chronic epilepsy. SE is also a common life-threatening condition in TBM and is associated with increased risk of mortality, disability, and epilepsy [5, $65,71,81]$, especially in developing countries $[5,34,82]$. The role of inflammation in the pathogenesis of epilepsy and seizure-induced brain injury has been recently confirmed by many studies $[83,84]$. SE itself provokes brain inflammation resulting in an increased tendency for seizures, severe brain injury, thus constitute a major risk for chronic epilepsy $[44,85]$. It is estimated that SE has a 3 -fold higher risk of acquired epilepsy compared with a single self-limited seizure [86]. Kim and colleagues had found that SE was the only significant clinical predictor of drug-resistance epilepsy at long-term follow-up [22].

\section{Tuberculoma}

Tuberculomas can occur at any age and can be either single or multiple, with the incidence being higher in pediatrics [87]. Parenchymal invasion in TBM followed by the development of tuberculoma(s) may induce chronic epilepsy with a latency period [88, 89], especially in HIV positive patients [90]. Bahemuka, M. et al. also has found that CNS tuberculoma was associated with refractory epilepsy [91]. In a study included 93 TBM patients with tuberculomas, seizures occurred in $22(23.6 \%)$ patients, and out of 63 followed patients, 35\% had concomitant epilepsy [92].

\section{Infarction}

In most of the reported studies, the frequency of stroke in TBM varied from 20 to 66\% [93-97]. The strokes associated with TBM are often ischemic and multifocal [96, 97]. These infarcts usually occur in areas supplied by the deep penetrating arteries such as internal capsules, basal ganglia, and thalamus, but infarctions in the cortical and subcortical regions are not uncommon [94, 96, 97]. However, many studies had reported that cortical and subcortical infarctions were more likely to induce convulsions compared to other regions $[48,67]$. Furthermore, cerebral infarctions tend to occur more commonly in children and more frequently result in generalized seizures rather than focal seizures [4]. A recently conducted study has detected infarction in 39\% of TBM patients, seizures had occurred in half of them, with only cortical and subcortical infarctions were significantly associated with seizure induction [48].

\section{Hippocampal sclerosis}

The involvement of mesial temporal lobe during CNS infection is common and has been reported in $64.3 \%$ of epilepsy patients after surgery [98]. In a study, hippocampal sclerosis was confirmed in most of the cases (76.5\%) with repetitive seizures or SE during the acute phase of encephalitis [99]. In a recent study, hippocampal sclerosis alone was reported in $30 \%$ of patients with chronic epilepsy as a sequel of TBM; while hippocampal sclerosis in combination with encephalomalacia was detected in $65 \%$ of the cases; with a latency period ranges from 5.3 to 6.5 years [88]. Therefore, hippocampal sclerosis could function as a prognostic factor for CNS infection-related epilepsy.

\section{Epileptic activity on EEG}

EEG is a valuable diagnostic tool for predicting further seizures following a first-unprovoked seizure [22]. EEG has been found to have a role in assessing the gravity of lesions and even to help in predicting the outcomes [100]. Focal spikes on EEG are more often associated with brain abnormalities that may induce recurrent seizures and chronic epilepsy [4]. Gunawan et al. have found a strong correlation between clinical seizures and EEG abnormalities; this study has also reported that EEG can be used to detect seizure activity and assess the risk of epilepsy in patients with TBM [30]. Therefore, a severe and persistent epileptic activity on EEG may predict recurrent seizures and chronic epilepsy.

\section{Treatment}

Early treatment of TBM with appropriate anti-TB drugs could reduce complications such as infarction, tuberculoma, or hydrocephalus; thereby decrease the incidence of late-onset seizures and acquired epilepsy. Beside the recommended anti-TB treatment and restoring internal homeostasis, TBM patients with seizures are in need of either short or long-term antiepileptic drugs (AEDs). After the first acute seizure, patients with TBM commonly experience recurrent seizure attacks unless treated with AEDs prophylaxis; or in the acute phase with benzodiazepines, then phenytoin/ fosphenytoin and subsequent maintenance therapy. Many epidemiological studies concluded that regardless of the etiology of seizure, the number of seizures occurring before adequate treatment is a paramount prognostic factor for predicting the patients' response to AEDs. Therefore, early treatment with AEDs is crucial and may significantly reduce the risk of chronic epilepsy following TBM infection [101-103].

Valproic acid and Levetiracetam are commonly used alternative agents [104-106], and AEDs use may be continued for a period of 3 to 6 months if the risk of 
recurrence is relatively high [107]. However, it is suggested to withhold Valproic acid use in TBM patients if possible due to the increased risk of hepatotoxicity [13]. The treatment of post-TBM epilepsy is usually similar to other symptomatic epilepsies. The choice of AED should be based on the seizure semiology [5]. But, drug interactions must always be considered in each individual case, as it may lead to either decreased efficacy or toxicity.

Since seizure generation is associated with an inflammatory response, the use of anti-inflammatory agents may reduce or suppress seizures [5]. A Cochrane meta-analysis has also concluded that adding 6-8 weeks' course of steroids may reduce TBM complications, including seizures, and improve the outcomes [108]. Moreover, neuroimaging is warranted in all cases to guide treatment, monitor progress, and assess the need for further intervention. Physicians should also be aware that although fluoroquinolones are a good alternative for the current anti-TB medications, they are known to exacerbate seizures and should be avoided in TBM patients with documented seizures [109]. A recently published meta-analysis has reported similar findings [46].

\section{Prognosis}

Although very limited data regarding the prognosis of TBM patients presented with seizures is available so far, seizure occurrence has been considered as a significant predictor of mortality [110], especially in children and HIV-positive patients $[40,111]$. Seizures increase the burden of disability among TBM patients and produce neurological deficits, thereby, increase the mortality and require a long-term antiepileptic treatment [110]. TBM Patients with seizures often have a worse prognosis relative to those without seizures [70]. A study from India found that TBM patients presented with seizures had a 2-fold increased risk of subsequent mechanical ventilation, and high mortality compared to those without seizures [112]. Another study included 478 TBM patients, has found that new-onset seizures were associated with a 4-fold risk of death and neurological disability [113]; many other studies had also reported relatively similar findings $[21,70,114]$.

TBM related seizures are more likely to associate with a better prognosis compared with viral encephalitis-induced seizures. Patients with viral encephalitis are approximately 16-fold more likely to develop chronic epilepsy relative to the general population [115]. Furthermore, it is estimated that up to $60 \%$ of patients with viral encephalitis continue to have recurrent seizures and epilepsy [116] compared to around 20\% of those with TBM [117-119]. Regardless of the etiology, aggressive control of clinical and subclinical seizures, especially prolonged or repetitive ones such as $\mathrm{SE}$, is the mainstay approach that may improve the therapeutic outcomes and prevent the development of chronic epilepsy in patients with TBM.

\section{Conclusion}

Seizures are a common finding in patients with TBM, and can occur at any time point of the disease course, especially in children. Neuroinflammation, diffuse brain injury, reactive gliosis, and mass effect contribute to the pathogenesis of seizures in TBM. The early-onset seizures in TBM patients may be attributed to meningeal irritation and cerebral oedema; while, the late seizures are usually associated with infarction, hydrocephalus, tuberculoma, and paradoxical response. Seizures in TBM are plonic seizures based on the underlying pathologies. The patient's age, repetitive seizures and SE, tuberculoma, infarction, hippocampal sclerosis, and persistent epileptic activity were reported to associate with increased risk of chronic epilepsy following TBM infection. Therefore, adequate treatment of TB infection along with early identification and management of seizures and other complications may reduce the risk of developing chronic epilepsy and improve the overall outcome in TBM patients.

\section{Abbreviations}

AEDs: Antiepileptic drugs; BBB: Blood-brain barrier; CNS: Central nervous system; CSF: Cerebrospinal fluid; EEG: Electroencephalography;

GTCS: Generalized tonic clonic seizures; HIV: Human immunodeficiency virus; ICP: Intracranial pressure; MRI: Magnetic resonance imaging; SE: Status epileptics; TB: Tuberculosis; TBM: Tuberculous meningitis

Acknowledgements

Not applicable.

\section{Authors' contributions}

AMTA: made substantial contributions to the conception and content of the study, drafted and revised the manuscript, read and approved the final manuscript. JML: drafted and revised the manuscript, read and approved the final manuscript. DZ: made substantial contributions to the conception and content of the study, revised the manuscript, read and approved the final manuscript.

\section{Funding}

None.

Availability of data and materials

Not applicable.

Ethics approval and consent to participate

Not applicable.

\section{Competing interests}

The authors declare that they have no competing interest.

\section{Author details}

'Department of Neurology, West China Hospital, Sichuan University, 37 Guo Xue Xiang st, Chengdu 610041, China. ${ }^{2}$ Faculty of Brain Sciences, UCL Queen Square Institute of Neurology, London WC1N 3BG, UK.

Received: 15 August 2019 Accepted: 9 January 2020

Published online: 30 January 2020

\section{References}

1. World Health Organization. Global tuberculosis report. 2013. Geneva: WHO; 2013.

2. Torok ME, Nguyen DB, Tran TH, Nguyen TB, Thwaites GE, Hoang TQ, et al. Dexamethasone and long-term outcome of tuberculous meningitis in Vietnamese adults and adolescents. PLoS One. 2011;6(12):e27821.

3. Brigo F, Ausserer H, Zuccoli G, Tezzon F, Nardone R. Seizure heralding tuberculous meningitis. Epileptic Disord. 2012;14(3):329-33. 
4. Patwari AK, Aneja S, Ravi RN, Singhal PK, Arora SK. Convulsions in tuberculous meningitis. J Trop Pediatr. 1996;42(2):91-7.

5. Singhi P. Infectious causes of seizures and epilepsy in the developing world. Dev Med Child Neurol. 2011:53(7):600-9.

6. Kingsley DP, Hendrickse WA, Kendall BE, Swash M, Singh V. Tuberculous meningitis: role of $C T$ in management and prognosis. J Neurol Neurosurg Psychiatry. 1987;50(1):30-6.

7. Zerihun G, Esscher E. Ten years' experience of tuberculous meningitis in children. Ethiop Med J. 1984;22(1):49-54.

8. Naughten E, Weindling AM, Newton R, Bower BD. Tuberculous meningitis in children. Recent experience in two English centres. Lancet. 1981;2(8253):973-5.

9. van Well GT, Paes BF, Terwee CB, Springer P, Roord JJ, Donald PR, et al. Twenty years of pediatric tuberculous meningitis: a retrospective cohort study in the western cape of South Africa. Pediatrics. 2009;123(1):e1-8.

10. Vezzani A, Aronica E, Mazarati A, Pittman QJ. Epilepsy and brain inflammation. Exp Neurol. 2013;244:11-21.

11. Dey A, Kang X, Qiu J, Du Y, Jiang J. Anti-Inflammatory Small Molecules To Treat Seizures and Epilepsy: From Bench to Bedside. Trends Pharmacol Sci. 2016;37(6):463-84.

12. Choi J, Nordli DR, Jr., Alden TD, DiPatri A, Jr., Laux L, Kelley K, et al. Cellular injury and neuroinflammation in children with chronic intractable epilepsy. J Neuroinflammation. 2009;6:38.

13. Murthy JM. Tuberculous meningitis: the challenges. Neurol India. 2010;58(5): 716-22.

14. Lincoln EM, Sordillo VR, Davies PA. Tuberculous meningitis in children. A review of 167 untreated and 74 treated patients with special reference to early diagnosis. J Pediatr. 1960;57(6):807-23.

15. Thomas MD, Chopra JS, Walia BN. Tuberculous meningitis (T.B.M.)(a clinical study of 232 cases). J Assoc Physicians India. 1977;25(9):633-9.

16. Tahernia AC. Tuberculous meningitis. Modern diagnosis, treatment and prognosis, as exemplified in 38 cases in southern Iran. Clin Pediatr (Phila). 1967:6(3):173-7.

17. Rao S, Bharucha PE, Bharucha EP. Prognosis in tuberculous meningitis. Indian Pediatr. 1970;7(5):257-61.

18. Bharucha PE, lyer CG, Bharucha EP, Deshpande DH. Tuberculous meningitis in children: a clinico-pathological evaluation of 24 cases. Indian Pediatr. 1969;6(5):282-90.

19. Garcia-Monco JC. Central nervous system tuberculosis. Neurol Clin. 1999; 17(4):737-59.

20. Sutlas PN, Unal A, Forta $H$, Senol S, Kirbas D. Tuberculous meningitis in adults: review of 61 cases. Infection. 2003;31(6):387-91.

21. Misra UK, Kalita J, Roy AK, Mandal SK, Srivastava M. Role of clinical, radiological, and neurophysiological changes in predicting the outcome of tuberculous meningitis: a multivariable analysis. J Neurol Neurosurg Psychiatry. 2000;68(3):300-3.

22. Kim MA, Park KM, Kim SE, Oh MK. Acute symptomatic seizures in CNS infection. Eur J Neurol. 2008;15(1):38-41.

23. Skoldenberg B, Forsgren M, Alestig K, Bergstrom T, Burman L, Dahlqvist E, et al. Acyclovir versus vidarabine in herpes simplex encephalitis. Randomised multicentre study in consecutive Swedish patients. Lancet. 1984;2(8405):707-11.

24. Whitley RJ, Alford CA, Hirsch MS, Schooley RT, Luby JP, Aoki FY, et al. Vidarabine versus acyclovir therapy in herpes simplex encephalitis. N Engl J Med. 1986;314(3):144-9.

25. Whitley RJ, Soong SJ, Dolin R, Galasso GJ, Ch'ien LT, Alford CA. Adenine arabinoside therapy of biopsy-proved herpes simplex encephalitis. National Institute of Allergy and Infectious Diseases collaborative antiviral study. N Engl J Med. 1977;297(6):289-94.

26. Arman F, Kaya D, Akgun Y, Kocagoz S. Tuberculous meningitis presenting with nonconvulsive status epilepticus. Epilepsy Behav. 2011;20(1):111-5.

27. Farinha NJ, Razali KA, Holzel H, Morgan G, Novelli VM. Tuberculosis of the central nervous system in children: a 20-year survey. J Infect. 2000;41(1):61-8.

28. Adole PS, Singh A, Kharbanda PS, Sharma S. Phenotypic interaction of simultaneously administered isoniazid and phenytoin in patients with tuberculous meningitisor tuberculoma having seizures. Eur J Pharmacol. 2013;714(1-3):157-62.

29. Karande S, Gupta V, Kulkarni M, Joshi A. Prognostic clinical variables in childhood tuberculous meningitis: an experience from Mumbai, India. Neurol India. 2005:53(2):191-5; discussion 5-6.

30. Gunawan PI, Saharso D. Seizure increases electroencephalographic abnormalities in children with tuberculous meningitis. Universa Medicina. 2016;34(3):161-7.
31. Marks DA, Kim J, Spencer DD, Spencer SS. Characteristics of intractable seizures following meningitis and encephalitis. Neurology. 1992:42(8):1513-8.

32. Friedman MJ, Sharieff GQ. Seizures in children. Pediatr Clin N Am. 2006; 53(2):257-77.

33. O'Brien TJ, Moses H, Cambier D, Cascino GD. Age of meningitis or encephalitis is independently predictive of outcome from anterior temporal lobectomy. Neurology. 2002;58(1):104-9.

34. Vezzani A, Fujinami RS, White HS, Preux PM, Blumcke I, Sander JW, et al. Infections, inflammation and epilepsy. Acta Neuropathol. 2016;131(2):211-34.

35. Annegers JF, Hauser WA, Beghi E, Nicolosi A, Kurland LT. The risk of unprovoked seizures after encephalitis and meningitis. Neurology. 1988; 38(9):1407-10.

36. Miftode EG, Dorneanu OS, Leca DA, Juganariu G, Teodor A, Hurmuzache M, et al. Tuberculous Meningitis in Children and Adults: A 10-Year Retrospective Comparative Analysis. PLoS One. 2015;10(7):e0133477.

37. Abdulaziz ATA, Ren YM, Li W, Li JM, Zhou D. Comparison of Standard and Intensified Regimens for HIV-Negative Adults With Tuberculous Meningitis inWest China: A Retrospective Observational Study. Front Neurol. 2019;10:626.

38. Qu J, Zhou T, Zhong C, Deng R, Lu X. Comparison of clinical features and prognostic factors in HIV-negative adults with cryptococcal meningitis and tuberculous meningitis: a retrospective study. BMC Infect Dis. 2017;17(1):51.

39. Zhang B, Lv K, Bao J, Lu C, Lu Z. Clinical and laboratory factors in the differential diagnosis of tuberculous and cryptococcal meningitis in adult HIV-negative patients. Intern Med. 2013;52(14):1573-8.

40. Bandyopadhyay SK, Bandyopadhyay R, Dutta A. Profile of tuberculous meningitis with or without HIV infection and the predicators of adverse outcome. West Indian Med J. 2009;58(6):589-92.

41. Lonnroth K, Jaramillo E, Williams BG, Dye C, Raviglione M. Drivers of tuberculosis epidemics: the role of risk factors and social determinants. Soc Sci Med. 2009:68(12):2240-6.

42. Sumaya CV, Simek M, Smith MH, Seidemann MF, Ferriss GS, Rubin W. Tuberculous meningitis in children during the isoniazid era. J Pediatr. 1975; 87(1):43-9.

43. Kennedy DH, Fallon RJ. Tuberculous meningitis. JAMA. 1979:241(3):264-8.

44. Bharucha NE, Raven RH, Nambiar VK. Review of seizures and status epilepticus in HIV and tuberculosis with preliminary view of Bombay hospital experience. Epilepsia. 2009;50(Suppl 12):64-6.

45. Kalita J, Bhoi SK, Betai S, Misra UK. Safety and efficacy of additional levofloxacin in tuberculous meningitis: A randomized controlled pilot study. Tuberculosis (Edinb). 2016;98:1-6.

46. Rizvi I, Malhotra HS, Garg RK, Kumar N, Uniyal R, Pandey S. Fluoroquinolones in the management of tuberculous meningitis: Systematic review and meta-analysis. J Infect. 2018;77(4):261-75.

47. Temmerman W, Dhondt A, Vandewoude K. Acute isoniazid intoxication: seizures, acidosis and coma. Acta Clin Belg. 1999;54(4):211-6.

48. Misra UK, Kumar M, Kalita J. Seizures in tuberculous meningitis. Epilepsy Res. 2018:148:90-5.

49. Marchi N, Granata T, Janigro D. Inflammatory pathways of seizure disorders. Trends Neurosci. 2014:37(2):55-65.

50. Janigro D. Are you in or out? Leukocyte, ion, and neurotransmitter permeability across the epileptic blood-brain barrier. Epilepsia. 2012; 53(Suppl 1):26-34

51. Marchi N, Angelov L, Masaryk T, Fazio V, Granata T, Hernandez N, et al. Seizure-promoting effect of blood-brain barrier disruption. Epilepsia. 2007; 48(4):732-42.

52. Zattoni M, Mura ML, Deprez F, Schwendener RA, Engelhardt B, Frei K, et al. Brain infiltration of leukocytes contributes to the pathophysiology of temporal lobe epilepsy. J Neurosci. 2011;31(11):4037-50.

53. Vezzani A, French J, Bartfai T, Baram TZ. The role of inflammation in epilepsy. Nat Rev Neurol. 2011;7(1):31-40.

54. Iori V, Frigerio F, Vezzani A. Modulation of neuronal excitability by immune mediators in epilepsy. Curr Opin Pharmacol. 2016;26:118-23.

55. Vezzani A, Viviani B. Neuromodulatory properties of inflammatory cytokines and their impact on neuronal excitability. Neuropharmacology. 2015;96(Pt A) 70-82.

56. Walker A, Russmann V, Deeg CA, von Toerne C, Kleinwort KJH, Szober C, et al. Proteomic profiling of epileptogenesis in a rat model: Focus on inflammation. Brain Behav Immun. 2016:53:138-58.

57. Rock RB, Olin M, Baker CA, Molitor TW, Peterson PK. Central nervous system tuberculosis: pathogenesis and clinical aspects. Clin Microbiol Rev. 2008; 21(2):243-61, table of contents. 
58. Harder E, Al-Kawi MZ, Carney P. Intracranial tuberculoma: conservative management. Am J Med. 1983;74(4):570-6.

59. Janner D, Kirk S, McLeary M. Cerebral tuberculosis without neurologic signs and with normal cerebrospinal fluid. Pediatr Infect Dis J. 2000; 19(8):763-4.

60. Udani PM, Parekh UC, Dastur DK. Neurological and related syndromes in CNS tuberculosis. Clinical features and pathogenesis. J Neurol Sci. 1971; 14(3):341-57.

61. Singhal BS, Bhagwati SN, Syed AH, Laud GW. Raised intracranial pressure in tuberculous meningitis. Neurol India. 1975;23(1):32-9.

62. Dastur DK, Lalitha VS, Udani PM, Parekh U. The brain and meninges in tuberculous meningitis-gross pathology in 100 cases and pathogenesis. Neurol India.1970;18(2):86-100.

63. Gupta SK, Bedi RS, Maini VK. Epileptiform seizureswith single conventional dose of isoniazid. Ind J Tub. 1984;31:19-21.

64. Kalita J, Prasad S, Misra UK. Predictors of paradoxical tuberculoma in tuberculous meningitis. Int J Tuberc Lung Dis. 2014;18(4):486-91.

65. Narayanan JT, Murthy JM. Nonconvulsive status epilepticus in a neurological intensive care unit: profile in a developing country. Epilepsia. 2007:48(5): 900-6.

66. El-Sayed MM, Adeuja AO. Intracranial tuberculomas: the Hofuf, Saudi Arabia experience. Afr J Med Med Sci. 2006;35(1):21-7.

67. Kalita J, Misra UK. EEG changes in tuberculous meningitis: a clinicoradiological correlation. Electroencephalogr Clin Neurophysiol. 1998; 107(1):39-43.

68. Patwari AK, Aneja S, Chandra D, Singhal PK. Long-term anticonvulsant therapy in tuberculous meningitis--a four-year follow-up. J Trop Pediatr. 1996:42(2):98-103.

69. Dunne JW, Summers QA, Stewart-Wynne EG. Non-convulsive status epilepticus: a prospective study in an adult general hospital. Q J Med. 1987; 62(238):117-26.

70. Hosoglu S, Geyik MF, Balik I, Aygen B, Erol S, Aygencel TG, et al. Predictors of outcome in patients with tuberculous meningitis. Int J Tuberc Lung Dis. 2002;6(1):64-70

71. Misra UK, Kalita J, Nair PP. Status epilepticus in central nervous system infections: an experience from a developing country. Am J Med. 2008 121(7):618-23

72. Tandon PN, Pathak SN. Tuberculosis of central nervous system. In:J.D. Spillane (Ed.), Tropical neurology. Oxford University press, London, 1973;37(51).

73. Gibbs F. Electroencephalography. Int J Neurol. 1963:4(123).

74. Westmoreland BF. EEG in cerebral inflammatory processes. Electroencephalography. 1987;70:259-73.

75. Li K, Tang H, Yang Y, LiQ, Zhou Y, Ren M, et al. Clinical features, long-term clinical outcomes, and prognostic factors of tuberculous meningitis in West China: a multivariate analysis of 154 adults. Expert Rev Anti Infect Ther 2017;15(6):629-35.

76. Smith SJ. EEG in the diagnosis, classification, and management of patients with epilepsy. J Neurol Neurosurg Psychiatry. 2005;76(Suppl 2):ii2-7.

77. Kaplan PW. The EEG in metabolic encephalopathy and coma. J Clin Neurophysiol. 2004;21(5):307-18.

78. Ramantani G, Holthausen $\mathrm{H}$. Epilepsy after cerebral infection: review of the literature and the potential for surgery. Epileptic Disord. 2017;19(2):117-36.

79. Lee JH, Lee BI, Park SC, Kim WJ, Kim JY, Park SA, et al. Experiences of epilepsy surgery in intractable seizures with past history of CNS infection. Yonsei medical journal. 1997;38(2):73-8.

80. Berkovic SF, Mclntosh AM, Kalnins RM, Jackson GD, Fabinyi GC, Brazenor GA et al. Preoperative MRI predicts outcome of temporal lobectomy: an actuarial analysis. Neurology. 1995;45(7):1358-63.

81. Murthy JM, Jayalaxmi SS, Kanikannan MA. Convulsive status epilepticus: clinical profile in a developing country. Epilepsia. 2007:48(12):2217-23.

82. Newton CR. Status epilepticus in resource-poor countries. Epilepsia. 2009; 50(Suppl 12):54-5.

83. Vezzani A, Granata T. Brain inflammation in epilepsy: experimental and clinical evidence. Epilepsia. 2005;46(11):1724-43.

84. Ravizza T, Gagliardi B, Noe F, Boer K, Aronica E, Vezzani A. Innate and adaptive immunity during epileptogenesis and spontaneous seizures: evidence from experimental models and human temporal lobe epilepsy. Neurobiol Dis. 2008;29(1):142-60.

85. Vezzani A, Balosso S, Aronica E, Ravizza T. Basic mechanisms of status epilepticus due to infection and inflammation. Epilepsia. 2009;50:56-7.
86. Vezzani A, Dingledine R, Rossetti AO. Immunity and inflammation in status epilepticus and its sequelae: possibilities for therapeutic application. Expert Rev Neurother. 2015;15(9):1081-92.

87. Jamieson D. Imaging intracranial tuberculosis in childhood. Pediatr Radiol. 1995;25(3):165-70

88. Park S, Hong JY, Lee MK, Koh HS, Kim EY. Hippocampal sclerosis and encephalomalacia as prognostic factors of tuberculous meningitis-related and herpes simplex encephalitis-related epilepsy. Seizure. 2011;20(7):570-4.

89. De Bittencourt P, Sander J, Mazer S. Viral, bacterial, fungal and parasitic infections associated with seizure disorders: Elsevier; 1999.

90. Martinez-Vazquez C, Bordon J, Rodriguez-Gonzalez A, de la FuenteAguado J, Sopena B, Gallego-Rivera A, et al.Cerebral tuberculoma--a comparative study in patients with and without HIV infection. Infection. 1995;23(3):149-53.

91. Bahemuka M, Murungi JH. Tuberculosis of the nervous system. A clinical, radiological and pathological study of 39 consecutive cases in Riyadh, Saudi Arabia. J Neurol Sci. 1989:90(1):67-76.

92. AlSemari A, Baz S, Alrabiah F, Al-Khairallah T, Qadi N, Kareem A, et al. Natura course of epilepsy concomitant with CNS tuberculomas. Epilepsy Res. 2012; 99(1-2):107-11.

93. Hsieh FY, Chia LG, Shen WC. Locations of cerebral infarctions in tuberculous meningitis. Neuroradiology. 1992;34(3):197-9.

94. Koh SB, Kim BJ, Park MH, Yu SW, Park KW, Lee DH. Clinical and laboratory characteristics of cerebral infarction in tuberculous meningitis: a comparative study. J Clin Neurosci. 2007;14(11):1073-7.

95. Anderson NE, Somaratne J, Mason DF, Holland D, Thomas MG. Neurological and systemic complications of tuberculous meningitis and its treatment at Auckland City Hospital, New Zealand. J Clin Neurosci. 2010;17(9):1114-8.

96. Shukla R, Abbas A, Kumar P, Gupta RK, Jha S, Prasad KN. Evaluation of cerebral infarction in tuberculous meningitis by diffusion weighted imaging J Infect. 2008:57(4):298-306.

97. Kalita J, Misra UK, Nair PP. Predictors of stroke and its significance in the outcome of tuberculous meningitis. J Stroke Cerebrovasc Dis. 2009;18(4): 251-8.

98. Lancman ME, Morris HH 3rd. Epilepsy after central nervous system infection: clinical characteristics and outcome after epilepsy surgery. Epilepsy Res. 1996;25(3):285-90

99. McGrath N, Anderson NE, Croxson MC, Powell KF. Herpes simplex encephalitis treated with acyclovir: diagnosis and long term outcome. J Neurol Neurosurg Psychiatry. 1997;63(3):321-6.

100. Luders H, Noachtar S. Atlas and classification of electroencephalography. Philadelphia: Saunders; 2006.

101. Altunbasak S, Herguner O, Burgut HR. Risk factors predicting refractoriness in epileptic children with partial seizures. J Child Neurol. 2007:22(2):195-9.

102. Berg AT, Levy SR, Novotny EJ, Shinnar S. Predictors of intractable epilepsy in childhood: a case-control study. Epilepsia. 1996;37(1):24-30.

103. MacDonald BK, Johnson AL, Goodridge DM, Cockerell OC, Sander JW, Shorvon SD. Factors predicting prognosis of epilepsy after presentation with seizures. Ann Neurol. 2000;48(6):833-41.

104. Patel NC, Landan IR, Levin J, Szaflarski J, Wilner AN. The use of levetiracetam in refractory status epilepticus. Seizure. 2006;15(3):137-41.

105. Rupprecht S, Franke K, Fitzek S, Witte OW, Hagemann G. Levetiracetam as a treatment option in non-convulsive status epilepticus. Epilepsy Res. 2007: 73(3):238-44.

106. Rossetti AO, Bromfield EB. Determinants of success in the use of oral levetiracetam in status epilepticus. Epilepsy Behav. 2006;8(3):651-4.

107. Murthy J. Acute symptomatic seizures: Clinical and etiological spectrum in developing countries. Epilepsy in tropics. Georgetown: Landes Bioscience; 2006. p. 133-43.

108. Prasad K, Singh MB. Corticosteroids for managing tuberculous meningitis. Cochrane Database Syst Rev. 2008:(1):CD002244.

109. Rali P, Arshad H, Bihler E. A case of Tuberculous meningitis with Tuberculoma in Nonimmunocompromised immigrant. Case Rep Pulmonol. 2016;2016:9016142.

110. Paganini H, Gonzalez F, Santander C, Casimir L, Berberian G, Rosanova MT. Tuberculous meningitis in children: clinical features and outcome in 40 cases. Scand J Infect Dis. 2000;32(1):41-5.

111. Ramzan A, Nayil K, Asimi R, Wani A, Makhdoomi R, Jain A. Childhood tubercular meningitis: an institutional experience and analysis of predictors of outcome. Pediatr Neurol. 2013:48(1):30-5. 
112. Misra UK, Kalita J, Betai S, Bhoi SK. Outcome of tuberculous meningitis patients requiring mechanical ventilation. J Crit Care. 2015;30(6):1365-9.

113. Gupta R, Kushwaha S, Thakur R, Jalan N, Rawat P, Gupta P, et al. Predictors of adverse outcome in patients of tuberculous meningitis in a multi-centric study from India. Indian J Tuberc. 2017;64(4):296-301.

114. Alarcon F, Moreira J, Rivera J, Salinas R, Duenas G, Van den Ende J.

Tuberculous meningitis: do modern diagnostic tools offer better prognosis prediction? Indian J Tuberc. 2013;60(1):5-14.

115. Misra UK, Tan CT, Kalita J. Viral encephalitis and epilepsy. Epilepsia. 2008; 49(Suppl 6):13-8.

116. Elbers JM, Bitnun A, Richardson SE, Ford-Jones EL, Tellier R, Wald RM, et al. A 12-year prospective study of childhood herpes simplex encephalitis: is there a broader spectrum of disease? Pediatrics. 2007;119(2):e399-407.

117. Philip N, William T, John DV. Diagnosis of tuberculous meningitis: challenges and promises. Malays J Pathol. 2015:37(1):1-9.

118. Davis LE, Shih JJ. CNS infections and epilepsy. In: The Epilepsies: Elsevier; 1999. p. 265-74

119. Sheller JR, Des Prez RM. CNS tuberculosis. Neurol Clin. 1986;4(1):143-58.

Ready to submit your research? Choose BMC and benefit from:

- fast, convenient online submission

- thorough peer review by experienced researchers in your field

- rapid publication on acceptance

- support for research data, including large and complex data types

- gold Open Access which fosters wider collaboration and increased citations

- maximum visibility for your research: over $100 \mathrm{M}$ website views per year

At BMC, research is always in progress.

Learn more biomedcentral.com/submissions 